\title{
PERBAIKAN METODE KERJA DAN PERANCANGAN FASILITAS KERJA UNTUK MENGURANGI RESIKO MUSCULOSKELETAL DISORDERS (MSDS) (Studi Kasus : CV. Graffity Labelindo)
}

\author{
Eri Achiraeniwati ${ }^{1}$, Nur Rahman As' Ad $^{2}$, Nova Nur Azizah ${ }^{3}$ \\ Jurusan Teknik Industri, Fakultas Teknik, Universitas Islam Bandung ${ }^{1,2)}$ \\ Bandung, Jawa Barat, Indonesia ${ }^{1,2}$ ) \\ E-Mail :eri_ach@yahoo.co.id',nur_asad@yahoo.co.id',novanazizah@gmail.com³
}

\begin{abstract}
All of the production activity in a company cannot be separated with the material handling activity. There are a lot of companies that still use the traditional work system in the material handling activity, namely manual material handling systems.

$C V$. Graffity Labelindo is one of company which conducts material handling mostly using human power, especially the material handling activities done by the lamination machine operators. This activities lifting materials about 6-15 $\mathrm{kg}$ from the bottom (floor) into the top, makes workers have to bent to lift the materials, and then carry the materials by hand while moving about 20-24 meters.. Based on the results of questionnaires Nordic Body Map the biggest complaint that perceived lamination machine operator found on the neck, arms, thighs, waist, and back.

The methods used in this research is OWAS (Ovako Working Analysis System). According to the data processing, the result shows that almost all the material handling activity done by the lamination machine is included in the risk category 3 (three) which is positions with harmful effects on the musculoskeletal system (high risk) an require the corrective action.

The corrective action done to reduce or prevent risks of musculoskeletal disorders on the operator lamination machine is designing work facilities and improvements to the working methods. The results of the improvements can lower risk category operators lamination machine into risk category 1 (one) as to its normal position without any effects that can interfere with the musculoskeletal system (low risk).
\end{abstract}

Keywords : Manual Material Handling, Musculoskeletal Disorders (MSDs), OWAS (Ovako Working Postural Analysis System).

\section{PENDAHULUAN}

Segala aktivitas produksi atau sistem kerja di perusahaan tidak terlepas dari peran sumber daya manusia. Perusahaan merupakan pengelola sumber daya manusia yang memiliki peran untuk menjamin faktor kenyamanan para pekerjanya seperti yang tertuang dalam pasal 86, UU No. 13 Tahun 2003 telah diatur oleh undang-undang untuk melindungi keselamatan pekerja/buruh guna mewujudkan produktivitas kerja yang optimal diselenggarakan upaya keselamatan dan kesehatan kerja.

Salah satu bentuk upaya perusahaan dalam meningkatkan keselamatan dan kesehatan kerja terhadap setiap pekerjanya dengan memperhatikan sistem kerja yang masih tradisional, yaitu aktivitas kerja manual yang dapat menimbulkan resiko kerja.

CV. Graffity Labelindo merupakan perusahaan percetakan, yang masih melakukan perpindahan material secara manual (manual handling). Aktivitas manual handling yang dilakukan oleh pekerja berupa pengangkutan material bahan mentah, bahan setengah jadi, atau barang jadi di setiap stasiun kerja yang semuanya melibatkan pekerja.

Berdasarkan hasil pengamatan dan wawancara terhadap setiap divisi didapatkan pekerjaan operator Mesin Laminasi mempunyai beban paling besar berdasarkan frekuensi posisi pengangkatan material, jarak angkut, dan jumlah keluhan. Aktivitas pemindahan material menyebabkan adanya keluhan sakit pada bagian leher, lengan, 
Tabel 1. Kuesioner Nordic Body Map

\begin{tabular}{|c|c|c|c|c|c|}
\hline \multirow{2}{*}{ No. } & \multirow{2}{*}{ JENIS KELAMIN } & \multicolumn{4}{|c|}{ TINGKAT KELUHAN } \\
\hline & & $\mathbf{A}$ & B & $\mathbf{C}$ & D \\
\hline 0 & Sakit / kaku di leher bagian atas & & & & \\
\hline 1 & Sakit / kaku di leher bagian bawah & & & & \\
\hline 2 & Sakit di bahu kiri & & & & \\
\hline 3 & Sakit di bahu kanan & & & & \\
\hline 4 & Sakit pada lengan atas kiri & & & & \\
\hline 5 & Sakit di punggung & & & & \\
\hline 6 & Sakit di lengan atas kanan & & & & \\
\hline 7 & Sakit pada pinggang & & & & \\
\hline 8 & Sakit pada bokong & & & & \\
\hline 9 & Sakit pada pantat & & & & \\
\hline 10 & Sakit pada siku kiri & & & & \\
\hline 11 & Sakit pada siku kanan & & & & \\
\hline 12 & Sakit pada lengan bawah kiri & & & & \\
\hline 13 & Sakit pada lengan bawah kanan & & & & \\
\hline 14 & Sakit pada pergelangan tangan kiri & & & & \\
\hline 15 & Sakit pada pergelangan tangan kanan & & & & \\
\hline 16 & Sakit pada tangan kiri & & & & \\
\hline 17 & Sakit pada tangan kanan & & & & \\
\hline 18 & Sakit pada paha kiri & & & & \\
\hline 19 & Sakit pada paha kanan & & & & \\
\hline 20 & Sakit pada lutut kiri & & & & \\
\hline 21 & Sakit pada lutut kanan & & & & \\
\hline 22 & Sakit pada betis kiri & & & & \\
\hline 23 & Sakit pada betis kanan & & & & \\
\hline 24 & Sakit pada pergelangan kaki kiri & & & & \\
\hline 25 & Sakit pada pergelangan kaki kanan & & & & \\
\hline 26 & Sakit pada kaki kiri & & & & \\
\hline 27 & Sakit pada kaki kanan & & & & \\
\hline
\end{tabular}

Keterangan : A: Tidak Sakit, B: Agak Sakit, C: Sakit, D: Sakit Sekali

paha, pinggang, dan punggung yang merupakan bagian dari jenis keluhan pada Musculoskeletal Disorders (MSDs). Berdasarkan penelitian Nurhayuning dan Paskarini (2015) adanya hubungan posisi kerja dengan risiko Musculoskeletal Disorders pada unit pengelasan. Hasil penelitian lain yang dlakukan Ulfah, Harwanti dan Joko (2014) terdapat hubungan antara sikap kerja dengan risiko Musculoskeletal Disorders pada pekerja Laundry. Tujuan penelitian ini mencari hubungan antara keluhan Musculoskeletal Disorders (MSDs) terhadap perbaikan metode kerja dan perancangan fasilitas kerja diperlukan untuk meminimasi tingkat resiko kerja.

\section{TINJAUAN PUSTAKA \\ 2.1. Ergonomi}

Menurut Sutalaksana (2006) dalam bukunya bahwa ergonomi ialah suatu cabang ilmu yang sistematis untuk memanfaatkan informasi - informasi mengenai sifat, kemampuan dan keterbatasan manusia untuk merancang suatu sistem kerja sehingga orang dapat hidup dan bekerja pada sistem itu dengan baik, yaitu mencapai tujuan yang diinginkan melalui pekerjaan itu, dengan efektif, aman, sehat, nyaman, dan efisien.

Informasi mengenai karakteristik manusia dalam melakukan pekerjaan yang digunakan sebagai dasar perancangan sistem kerja dengan sasaran meminimasi risiko kerja yang akan dialami pekerja dengan sifat 
pekerjaan yang dilakukan berulang dan dalam rentang waktu yang lama.

Risiko kerja dapat berupa keluhan yang dialami pekerja pada setiap segemen tubuh pekerja yang disebut dengan musculoskeletal disorder (MSDs). Menurut Tarwaka (2004) keluhan musculoskeletal adalah keluhan pada bagian-bagian otot skeletal yang dirasakan oleh seseorang mulai dari keluhan sangat ringan sampai sangat sakit.

Apabila otot menerima beban statis secara berulang dalam waktu yang lama, akan dapat menyebabkan keluhan berupa kerusakan pada sendi, ligamen dan tendon. Keluhan hingga kerusakan inilah yang biasanya di istilahkan dengan keluhan Musculoskeletal disorsders (MSDs) atau cedera pada sistem muskuloskeletal.

Kuesioner Nordic Body Map merupakan alat yang dapat mengetahui bagian-bagian otot yang mengalami keluhan dengan tingkat keluhan mulai dari Tidak Sakit (TS), agak sakit (AS), Sakit (S) dan Sangat Sakit (SS) (Tarwaka, 2004). Bentuk kuesioner Nordic Body Map pada tabel 1.

\subsection{Ovako Working Analysis System (OWAS)}

Menurut Anggraini dan Pratama (2012) metode OWAS memberikan informasi mengenai penilaian postur tubuh pada saat bekerja sehingga dapat melakukan evaluasi dini atas risiko kecelakaan tubuh manusia yang terdiri atas beberapa bagian penting, yaitu Punggung (back), Lengan ( $\mathrm{arm}$ ), Kaki (leg), dan Beban kerja (load).

Penilaian tersebut digabungkan untuk melakukan perbaikan kondisi bagian postur tubuh yang berisiko terhadap kecelakaan. Penilaian terhadap gerakan atau postur tubuh pada saat bekerja untuk setiap segmen terdapat pada gambar 1 sampai gambar 3 .

Sikap punggung, penilaian pada punggung (back) diberikan nilai $1-4$.

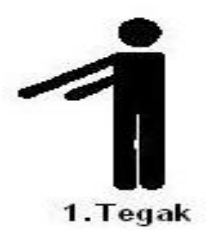

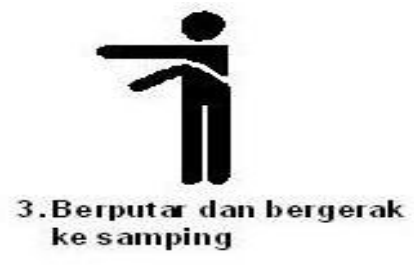

Gambar 1. Penilaian Punggung

Sikap lengan, penilaian pada lengan (arm) diberikan nilai $1-3$.

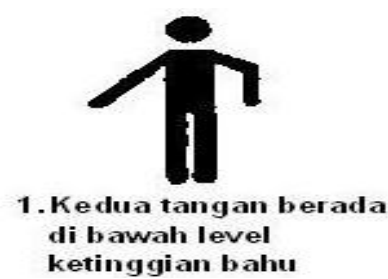

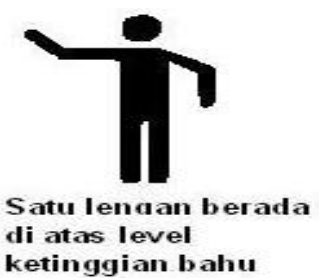

Gambar 2 Penilaian Lengan

Sumber: Anggraini \& Pratama (2012).

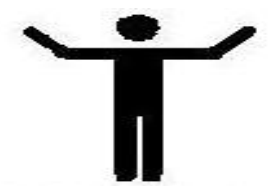

3. Kedua tangan berada di at as level ketinggian bahu

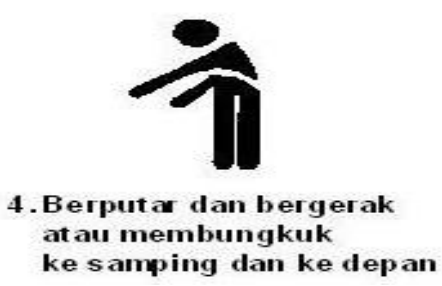

Sumber : Anggraini \& Pratama (2012). 
Tabel 2 Penilaian Sikap Kerja (Sumber: Karhu (1981) dalam Wijaya (2008))

\begin{tabular}{|c|c|c|}
\hline Kategori Resiko & Efek Pada Sistem Muskuloskeletal & Tindakan Perbaikan \\
\hline 1 & $\begin{array}{l}\text { Posisi normal tanpa efek yang dapat } \\
\text { menggenggu sistem musculoskeletal } \\
\text { (resiko rendah) }\end{array}$ & Tidak diperlukan perbaikan \\
\hline 2 & $\begin{array}{l}\text { Posisi yang berpotensi menyebabkan } \\
\text { kerusakan pada sistem musculoskeletal } \\
\text { (resiko sedang) }\end{array}$ & $\begin{array}{l}\text { Tidak perbaikan mungkin } \\
\text { diperlukan }\end{array}$ \\
\hline 3 & $\begin{array}{l}\text { Posisi dengan efek berbahaya pada sistem } \\
\text { musculoskeletal (resiko tinggi) }\end{array}$ & $\begin{array}{l}\text { Tindakan korektif } \\
\text { diperlukan segera }\end{array}$ \\
\hline 4 & $\begin{array}{l}\text { Posisi dengan efek sangat berbahaya pada } \\
\text { sistem musculoskeletal (resiko sangat } \\
\text { tinggi) }\end{array}$ & $\begin{array}{l}\text { Tindakan korektif } \\
\text { diperlukan segera mungkin }\end{array}$ \\
\hline
\end{tabular}

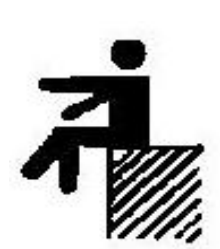

1.Duduk

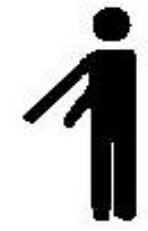

2.Berdiri dengan keadaan kedua kaki lurus

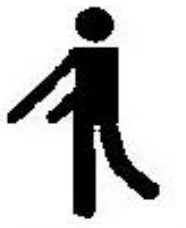

3.Berdiri dengan beban berada pada salah satu kaki

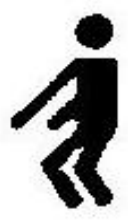

4.Berdiri dengan kedua kaki lut ut sedikit tertekuk

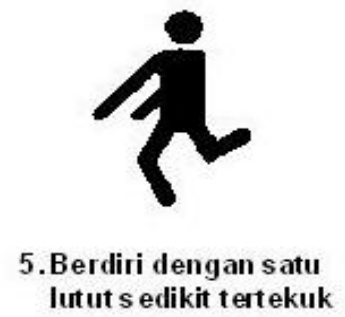

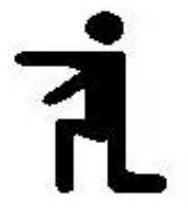

6.Jongkok dengan satu dan/atau dua kaki

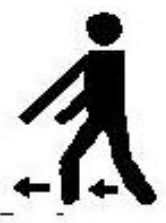

7.Bergerak atau berpindah

Gambar 3 Penilaian Kaki.

Sumber: Anggraini \& Pratama (2012)

Berat beban, penilaian pada beban (load) diberikan nilai $1-3$.

1. Berat beban kurang dari $10 \mathrm{Kg}(\mathrm{W}=10 \mathrm{Kg})$.

2. Berat beban $10 \mathrm{Kg}-20 \mathrm{Kg}(10 \mathrm{Kg}<\mathrm{W}=20 \mathrm{Kg})$.

3. Berat beban lebih besar dari $20 \mathrm{Kg}(\mathrm{W}>20 \mathrm{Kg})$. 
Tabel 3. Kategori Tindakan Kerja OWAS Sumber: Anggraini \& Pratama (2012)

\begin{tabular}{|c|c|c|c|c|c|c|c|c|c|c|c|c|c|c|c|c|c|c|c|c|c|c|c|}
\hline \multirow[b]{2}{*}{ Back } & \multirow[b]{2}{*}{ Arms } & \multicolumn{3}{|c|}{1} & \multicolumn{3}{|c|}{2} & \multicolumn{3}{|c|}{3} & \multicolumn{3}{|c|}{4} & \multicolumn{3}{|c|}{5} & \multicolumn{3}{|c|}{6} & \multicolumn{3}{|c|}{7} & \multirow{2}{*}{$\begin{array}{c}\text { Legs } \\
\text { Use } \\
\text { Offorce }\end{array}$} \\
\hline & & 1 & 2 & 3 & 1 & 2 & 3 & 1 & 2 & 3 & 1 & 2 & 3 & 1 & 2 & 3 & 1 & 2 & 3 & 1 & 2 & 3 & \\
\hline \multirow{3}{*}{1} & 1 & 1 & 1 & 1 & 1 & 1 & 1 & 1 & 1 & 1 & 2 & 2 & 2 & 2 & 2 & 2 & 1 & 1 & 1 & 1 & 1 & 1 & \\
\hline & 2 & 1 & 1 & 1 & 1 & 1 & 1 & 1 & 1 & 1 & 2 & 2 & 2 & 2 & 2 & 2 & 1 & 1 & 1 & 1 & 1 & 1 & \\
\hline & 3 & 1 & 1 & 1 & 1 & 1 & 1 & 1 & 1 & 1 & 2 & 2 & 2 & 2 & 2 & 2 & 1 & 1 & 1 & 1 & 1 & 1 & \\
\hline \multirow{3}{*}{2} & 1 & 2 & 2 & 3 & 2 & 2 & 3 & 2 & 2 & 3 & 3 & 3 & 3 & 3 & 3 & 3 & 3 & 2 & 2 & 2 & 3 & 3 & \\
\hline & 2 & 2 & 2 & 3 & 2 & 2 & 3 & 2 & 3 & 3 & 3 & 4 & 4 & 3 & 4 & 4 & 3 & 3 & 4 & 2 & 3 & 4 & \\
\hline & 3 & 3 & 3 & 4 & 2 & 2 & 3 & 3 & 3 & 3 & 3 & 4 & 4 & 4 & 4 & 4 & 4 & 4 & 4 & 2 & 3 & 4 & \\
\hline \multirow{3}{*}{3} & 1 & 1 & 1 & 1 & 1 & 1 & 1 & 1 & 1 & 2 & 3 & 3 & 3 & 4 & 4 & 4 & 4 & 1 & 1 & 1 & 1 & 1 & \\
\hline & 2 & 2 & 2 & 3 & 1 & 1 & 1 & 1 & 1 & 2 & 4 & 4 & 4 & 4 & 4 & 4 & 4 & 3 & 3 & 1 & 1 & 1 & \\
\hline & 3 & 2 & 2 & 3 & 1 & 1 & 1 & 2 & 3 & 4 & 4 & 4 & 4 & 4 & 4 & 4 & 4 & 4 & 4 & 2 & 3 & 4 & \\
\hline \multirow{3}{*}{4} & 1 & 2 & 3 & 3 & 2 & 2 & 3 & 2 & 2 & 3 & 4 & 4 & 4 & 4 & 4 & 4 & 4 & 4 & 4 & 2 & 3 & 4 & \\
\hline & 2 & 3 & 3 & 4 & 2 & 3 & 4 & 3 & 3 & 4 & 4 & 4 & 4 & 4 & 4 & 4 & 4 & 4 & 4 & 2 & 3 & 4 & \\
\hline & 3 & 4 & 4 & 2 & 3 & 4 & 3 & 3 & 4 & 4 & 4 & 4 & 4 & 4 & 4 & 4 & 4 & 4 & 4 & 2 & 3 & 4 & \\
\hline
\end{tabular}

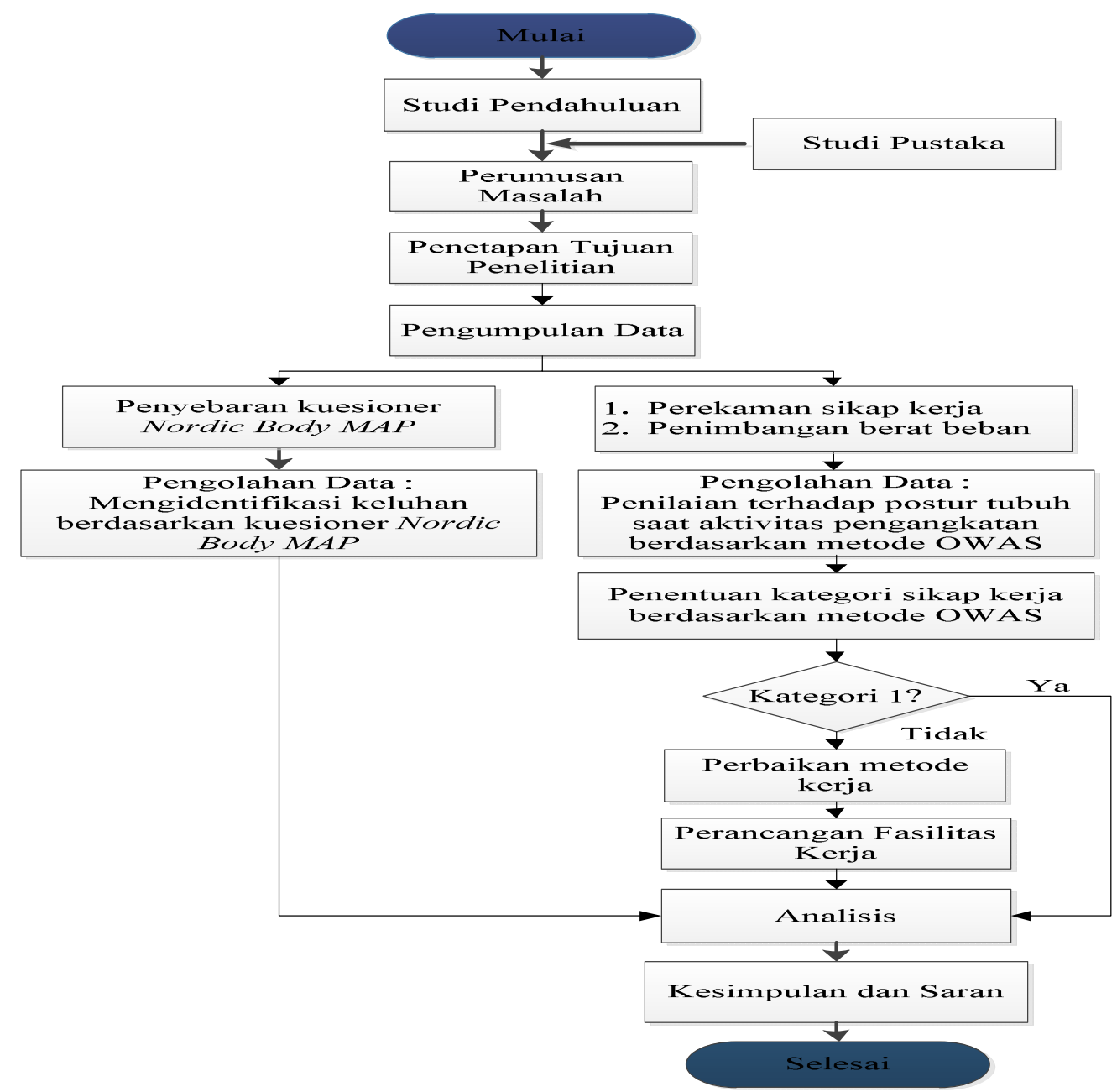

Gambar 4. Flowchart Metodologi Penelitian.

Hasil dari analisa metode OWAS diberi penilaian kedalam 4 kategori skala sikap kerja pada tabel 2. Hasil akhir dari analisa OWAS secara keseluruhan dimasukkan kedalam tabel yang disebut tabel kategori tindakan kerja OWAS. Tabel katagori tindakan kerja pada tabel 3. 
Tabel 4 Data Umur Pekerja

\begin{tabular}{c|c|c|c|c|c}
\hline No & Nama & Umur (Tahun) & $\begin{array}{c}\text { Pendidikan } \\
\text { Terakhir }\end{array}$ & Status & $\begin{array}{c}\text { Pengalaman } \\
\text { Kerja } \\
\text { (Tahun) }\end{array}$ \\
\hline 1 & Iwan & 25 & SMA & Belum Kawin & 6 \\
2 & Iman & 23 & SMP & Belum Kawin & 4 \\
3 & Cicin & 22 & SMP & Belum Kawin & 6 \\
\hline
\end{tabular}

Tabel 5 Data Berat Beban

\begin{tabular}{c|c|c}
\hline Pekerja & Jenis Beban yang di Angkat & Berat (Kg) \\
\hline Operator 1 & Plastik Roll & 25 \\
Operator 2 & Hangtag Laminasi & 22 \\
Operator 3 & Hangtag Laminasi & 18 \\
\hline
\end{tabular}

Tabel 6 Rekapitulasi Hasil Kuesioner Nordic Body Map

\begin{tabular}{|c|c|c|c|c|c|c|c|c|c|}
\hline \multirow{3}{*}{ No. } & \multirow{3}{*}{ JENIS KELAMIN } & \multicolumn{8}{|c|}{ TINGKAT KELUHAN } \\
\hline & & \multicolumn{2}{|c|}{$\mathbf{A}$} & \multicolumn{2}{|c|}{ B } & \multicolumn{2}{|c|}{$\mathbf{C}$} & \multicolumn{2}{|c|}{ D } \\
\hline & & Jml & $\%$ & Jml & $\%$ & $\mathbf{J m l}$ & $\%$ & $\mathbf{J m l}$ & $\%$ \\
\hline 0 & Sakit / kaku di leher bagian atas & & & 3 & 100 & & & & \\
\hline 1 & Sakit / kaku di leher bagian bawah & & & 3 & 100 & & & & \\
\hline 2 & Sakit di bahu kiri & & & 1 & 33.3 & 2 & 66.7 & & \\
\hline 3 & Sakit di bahu kanan & & & 1 & 33.3 & 2 & 66.7 & & \\
\hline 4 & Sakit pada lengan atas kiri & & & & & 2 & 66.7 & & \\
\hline 5 & Sakit di punggung & & & & & 3 & 100 & & \\
\hline 6 & Sakit di lengan atas kanan & & & & & 2 & 66.7 & & \\
\hline 7 & Sakit pada pinggang & & & 1 & 33.3 & 2 & 66.7 & & \\
\hline 8 & Sakit pada bokong & & & 1 & 33.3 & & & & \\
\hline 9 & Sakit pada pantat & & & & & & & & \\
\hline 10 & Sakit pada siku kiri & & & 1 & 33.3 & & & & \\
\hline 11 & Sakit pada siku kanan & & & 1 & 33.3 & & & & \\
\hline 12 & Sakit pada lengan bawah kiri & & & 2 & 66.7 & & & & \\
\hline 13 & Sakit pada lengan bawah kanan & & & 1 & 33.3 & 2 & 66.7 & & \\
\hline 14 & Sakit pada pergelangan tangan kiri & & & 1 & 33.3 & & & & \\
\hline 15 & Sakit pada pergelangan tangan kanan & & & 1 & 33.3 & & & & \\
\hline 16 & Sakit pada tangan kiri & & & 2 & 66.7 & 1 & 33.3 & & \\
\hline 17 & Sakit pada tangan kanan & & & 2 & 66.7 & 1 & 33.3 & & \\
\hline 18 & Sakit pada paha kiri & & & 1 & 33.3 & & & & \\
\hline 19 & Sakit pada paha kanan & & & 1 & 33.3 & & & & \\
\hline 20 & Sakit pada lutut kiri & & & & & & & & \\
\hline 21 & Sakit pada lutut kanan & & & & & & & & \\
\hline 22 & Sakit pada betis kiri & & & 3 & 100 & & & & \\
\hline 23 & Sakit pada betis kanan & & & 3 & 100 & & & & \\
\hline 24 & Sakit pada pergelangan kaki kiri & & & & & & & & \\
\hline 25 & Sakit pada pergelangan kaki kanan & & & & & & & & \\
\hline 26 & Sakit pada kaki kiri & & & & & & & & \\
\hline 27 & Sakit pada kaki kanan & & & & & & & & \\
\hline
\end{tabular}




\section{METODOLOGI PENELITIAN}

Penelitian ini dilaksanakan melalui beberapa tahapan sistematis dan saling berkaitan antara satu tahapan dengan tahapan lainnya. Keseluruhan tahapan penelitian digambarkan ke dalam skema flowchart pada gambar 4.

\section{PENGUMPULAN DAN PENGOLAHAN DATA}

Data yang dikumpulkan meliputi hasil penyebaran kuesioner Nordic Body map, umur pekerja dan berat beban angkat, perekaman sikap kerja. Umur pekerja dan beban angkat pada tabel 4 dan 5. Data berat beban merupakan berat material yang di angkat operator mesin laminasi dalam melakukan aktivitas manual material handling. Jenis beban yang diangkat, dan berat beban yang dilakukan 3 (tiga) operator mesin laminasi. Perekaman sikap kerja dilakukan dengan pengambilan gambar terhadap aktivitas pemindahan material yang dilakukan 3 (tiga) operator mesin laminasi.

\subsection{Pengolahan Data}

\subsubsection{Kuesioner Nordic Body Map}

Berdasarkan hasil penyebaran kuesioner Nordic Body Map kepada 3 (tiga) pekerja bagian operator mesin Laminasi diperoleh hasil keluhan yang dirasakan pekerja pada beberapa bagian otot. Rekapitulasi keluhan bagian otot yang dirasakan dari ketiga operator mesin laminasi terdapat pada tabel 6. Rekapitulasi kuesioner Nordic Body Map dalam bentuk diagram pada gambar 5 .

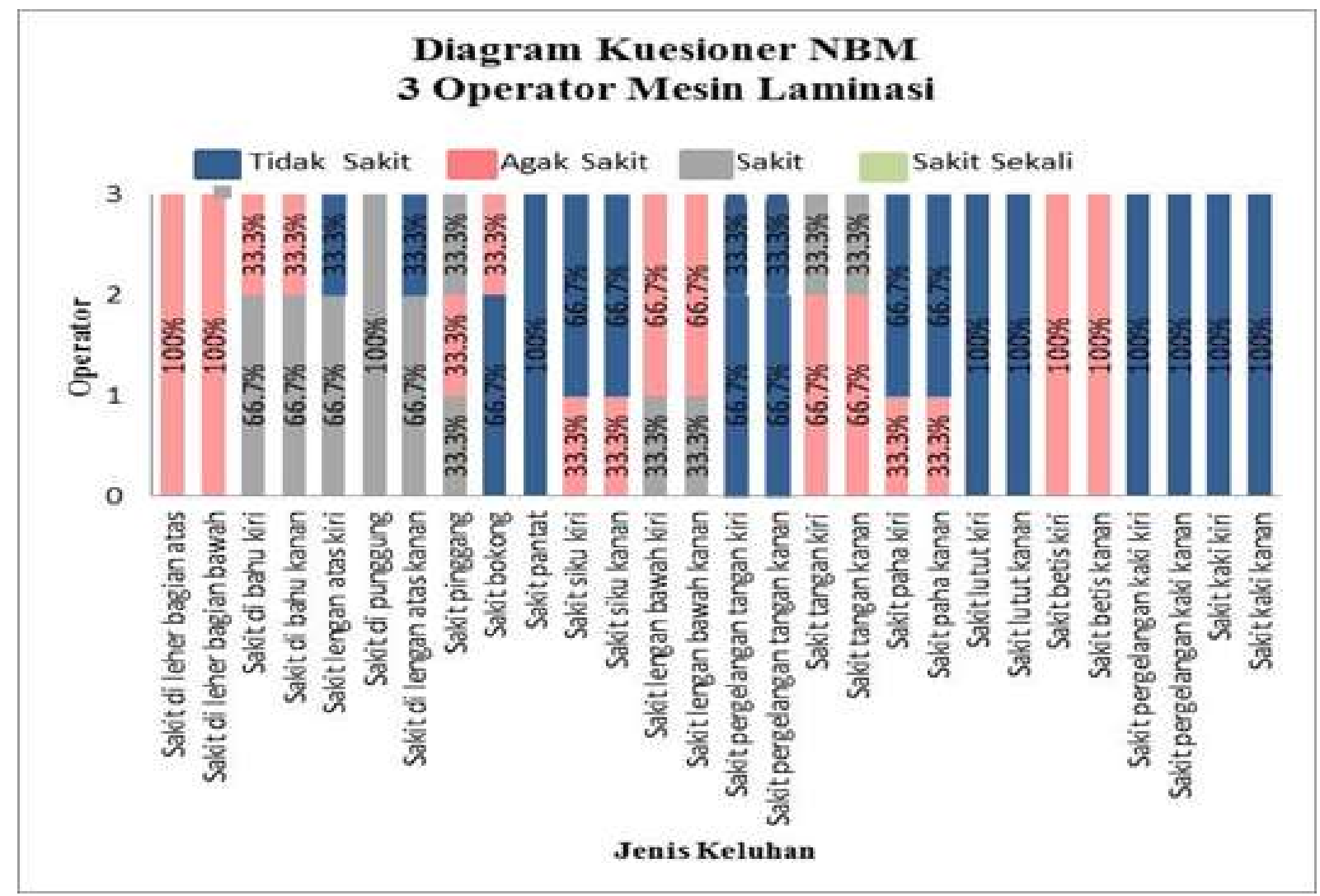

Gambar 5. Diagram Kuesioner Nordic Body Map.

\subsubsection{Penilaian Postur Tubuh (Coding Postures)}

Penilaian terhadap postur tubuh pada saat aktivitas pengangkatan material bertujuan untuk menentukan kategori resiko kerja operator mesin laminasi. Rekapitulasi penilaian postur tubuh (coding postures) rekaman sikap kerja setiap aktivitas pemindahan material pada 3 (tiga) operator mesin laminasi terdapat pada tabel 7 . 
Tabel 7 Rekapitulasi Coding Postures Rekaman Sikap Kerja

\begin{tabular}{|c|c|c|c|}
\hline No & Pekerja & Aktivitas & Kode \\
\hline \multirow{3}{*}{1} & \multirow{3}{*}{ Operator 1} & Mengangkat & 2143 \\
\hline & & Membawa & 1173 \\
\hline & & Menurunkan & 2143 \\
\hline \multirow{3}{*}{2} & \multirow{3}{*}{ Operator 2} & Mengangkat & 2123 \\
\hline & & Membawa & 2173 \\
\hline & & Menurunkan & 2143 \\
\hline \multirow{3}{*}{3} & \multirow{3}{*}{ Operator 3} & Mengangkat & 2152 \\
\hline & & Membawa & 2172 \\
\hline & & Menurunkan & 2142 \\
\hline
\end{tabular}

Tabel 8 Rekapitulasi Penentuan Kategori Resiko Kerja

\begin{tabular}{|c|c|c|c|c|c|c|}
\hline No & Pekerja & Aktivitas & $\begin{array}{l}\text { Kode } \\
\text { Postur }\end{array}$ & $\begin{array}{c}\text { Kode } \\
\text { Resiko }\end{array}$ & $\begin{array}{l}\text { Efek pada Sistem } \\
\text { Muskuloskeletal }\end{array}$ & Keterangan \\
\hline \multirow{3}{*}{1} & \multirow{3}{*}{ Operator 1} & Mengangkat & 2143 & 3 & $\begin{array}{l}\text { Posisi dengan efek } \\
\text { berbahaya pada sistem } \\
\text { Muskuloskeletal } \\
\text { (resiko tinggi), } \\
\text { tindakan korektif } \\
\text { diperlukan segera. }\end{array}$ & $\begin{array}{l}\text { Punggung membungkuk } \\
\text { ke depan, kedua lengan } \\
\text { berada dibawah bahu, } \\
\text { berdiri dengan kedua } \\
\text { lutut sedikit tertekuk, } \\
\text { dengan berat beban } \\
\text { sebesar } 25 \mathrm{Kg} \text {. }\end{array}$ \\
\hline & & Membawa & 1173 & 1 & $\begin{array}{l}\text { Posisi normal tanpa } \\
\text { efek yang dapat } \\
\text { mengganggu sistem } \\
\text { Muskuloskeletal } \\
\text { (resiko rendah), tidak } \\
\text { diperlukan perbaikan. }\end{array}$ & $\begin{array}{l}\text { Punggung berdiri tegak, } \\
\text { kedua lengan berada } \\
\text { dibawah bahu, kedua } \\
\text { kaki bergerak atau } \\
\text { berpindah, dengan berat } \\
\text { beban sebesar } 25 \mathrm{Kg} \text {. }\end{array}$ \\
\hline & & Menrunkan & 2143 & 3 & $\begin{array}{l}\text { Posisi dengan efek } \\
\text { berbahaya pada sistem } \\
\text { Muskuloskeletal } \\
\text { (resiko tinggi), } \\
\text { tindakan korektif } \\
\text { diperlukan segera. }\end{array}$ & $\begin{array}{l}\text { Punggung membungkuk } \\
\text { ke depan, kedua lengan } \\
\text { berada dibawah bahu, } \\
\text { berdiri dengan kedua } \\
\text { lutut sedikit tertekuk, } \\
\text { dengan berat beban } \\
\text { sebesar } 25 \mathrm{Kg}\end{array}$ \\
\hline \multirow{3}{*}{2} & \multirow{3}{*}{ Operator 2} & Mengangkat & 2123 & 3 & $\begin{array}{l}\text { Posisi dengan efek } \\
\text { berbahaya pada sistem } \\
\text { Muskuloskeletal } \\
\text { (resiko tinggi), } \\
\text { tindakan korektif } \\
\text { diperlukan segera. }\end{array}$ & $\begin{array}{c}\text { Punggung membungkuk } \\
\text { ke depan, kedua lengan } \\
\text { berada dibawah bahu, } \\
\text { berdiri dengan kaki } \\
\text { lurus, dengan berat } \\
\text { beban sebesar } 22 \mathrm{Kg}\end{array}$ \\
\hline & & Membawa & 2173 & 3 & $\begin{array}{l}\text { Posisi dengan efek } \\
\text { berbahaya pada sistem } \\
\text { Muskuloskeletal } \\
\text { (resiko tinggi), } \\
\text { tindakan korektif } \\
\text { diperlukan segera. }\end{array}$ & $\begin{array}{l}\text { Punggung membungkuk } \\
\text { ke depan, kedua lengan } \\
\text { berada dibawah bahu, } \\
\text { berdiri dengan kedua } \\
\text { kaki bergerak atau } \\
\text { berpindah, dengan berat } \\
\text { beban sebesar } 22 \mathrm{Kg}\end{array}$ \\
\hline & & Menrunkan & 2143 & 3 & $\begin{array}{l}\text { Posisi dengan efek } \\
\text { berbahaya pada sistem } \\
\text { Muskuloskeletal } \\
\text { (resiko tinggi), } \\
\text { tindakan korektif } \\
\text { diperlukan segera. }\end{array}$ & $\begin{array}{c}\text { Punggung membungkuk } \\
\text { ke depan, kedua lengan } \\
\text { berada dibawah bahu, } \\
\text { berdiri dengan kedua } \\
\text { lutut sedikit tertekuk, } \\
\text { dengan berat beban } \\
\text { sebesar } 22 \mathrm{Kg}\end{array}$ \\
\hline
\end{tabular}




\begin{tabular}{|c|c|c|c|c|c|c|}
\hline No & Pekerja & Aktivitas & $\begin{array}{l}\text { Kode } \\
\text { Postur }\end{array}$ & $\begin{array}{c}\text { Kode } \\
\text { Resiko }\end{array}$ & $\begin{array}{l}\text { Efek pada Sistem } \\
\text { Muskuloskeletal }\end{array}$ & Keterangan \\
\hline \multirow{3}{*}{3} & \multirow{3}{*}{ Operator 3} & Mengangkat & 2152 & 3 & $\begin{array}{l}\text { Posisi dengan efek } \\
\text { berbahaya pada sistem } \\
\text { Muskuloskeletal } \\
\text { (resiko tinggi), } \\
\text { tindakan korektif } \\
\text { diperlukan segera. }\end{array}$ & $\begin{array}{l}\text { Punggung membungkuk } \\
\text { ke depan, kedua lengan } \\
\text { berada dibawah bahu, } \\
\text { berdiri dengan satu lutut } \\
\text { sedikit tertekuk, dengan } \\
\text { berat beban sebesar } 18 \\
\text { Kg }\end{array}$ \\
\hline & & Membawa & 2172 & 3 & $\begin{array}{l}\text { Posisi dengan efek } \\
\text { berbahaya pada } \\
\text { Muskuloskeletal } \\
\text { (resiko tinggi), } \\
\text { tindakan korektif } \\
\text { diperlukan segera. }\end{array}$ & $\begin{array}{l}\text { Punggung berdiri tegak, } \\
\text { kedua lengan berada } \\
\text { dibawah bahu, kedua } \\
\text { kaki bergerak atau } \\
\text { berpindah, dengan berat } \\
\text { beban sebesar } 18 \mathrm{Kg} \text {. }\end{array}$ \\
\hline & & Menrunkan & 2142 & 3 & $\begin{array}{l}\text { Posisi dengan efek } \\
\text { berbahaya pada sistem } \\
\text { Muskuloskeletal } \\
\text { (resiko tinggi), } \\
\text { tindakan korektif } \\
\text { diperlukan segera. }\end{array}$ & $\begin{array}{l}\text { Punggung membungkuk } \\
\text { ke depan, kedua lengan } \\
\text { berada dibawah bahu, } \\
\text { berdiri dengan kedua } \\
\text { lutut sedikit tertekuk, } \\
\text { dengan berat beban } \\
\text { sebesar } 18 \mathrm{Kg} \text {. }\end{array}$ \\
\hline
\end{tabular}

\subsubsection{Penentuan Kategori Risiko Kerja}

Penentuan kategori resiko kerja merupakan proses mengolah hasil dari penilaian terhadap postur tubuh (coding postures) yaitu berupa kode postur kerja. Tabel 8 merupakan penentuan kategori resiko kerja pada pekerja 1 untuk setiap aktivitas pemindahan material.

\section{ANALISIS}

\subsection{Analisis Kuesioner}

\section{Nordic Body Map}

Prosentase keluhan pada operator mesin laminasi akan semakin besar jika aktivitas pemindahan material dilakukan dengan waktu yang berkepanjangan dan faktor usia yang melakukan ativitas tersebut, menurut Chaffin (1979) dan Guo dkk (1995) dalam Tarwaka.dkk (2004) menyatakan bahwa pada umumnya keluhan musculoskeletal mulai dirasakan pada usia kerja, yaitu antara 25-65 tahun.
Hal ini terbukti bahwa operator 1 memiliki banyak keluhan dikarenakan operator 1 telah bekerja selama 6 tahun dan berusia 25 tahun, operator 2 cukup banyak mengalami keluhan karena operator 2 baru bekerja selama 4 tahun dan berusia 23 tahun, sedangkan operator 3 mengalami sedikit keluhan meskipun telah bekerja selama 6 tahun tetapi usia saat ini baru 21 tahun.

\subsection{Analisis Penentuan Resiko Kerja}

Hasil dari penentuan resiko kerja terhadap ketiga operator menggunakan metode manual dan menggunakan software WinOWAS yaitu di dominasi kategori resiko 3 (tiga) yang berarti posisi dengan efek berbahaya pada sistem muskuloskeletal (resiko tinggi), dan tindakan korektif diperlukan segera. Perbaikan metode kerja dan perancangan fasilitas kerja merupakan tindakan korektif yang dilakukan untuk memperbaiki posisi kerja yang dapat membahayakan sistem musculoskeletal dalam aktivitas pemindahan material yang dilakukan operator mesin laminasi. 
Tabel 9 Metode Perbaikan Aktivitas Mengangkat Operator 1

\begin{tabular}{l|l}
\hline \multicolumn{1}{c|}{ Metode Awal } & \multicolumn{1}{c}{ Metode Perbaikan } \\
\hline Punggung membungkuk ke depan & Punggung tegak \\
\hline Kedua lengan berada dibawah bahu & Kedua lengan berada dibawah bahu \\
\hline Berdiri dengan kedua lutut sedikit tertekuk & Berdiri dengan kedua kaki lurus \\
\hline Berat badan sebesar 25 Kg 3 & Berat badan sebesar 25 Kg \\
\hline Kode 2143 & Kode 1123 \\
\hline Kategori resiko 3 & Kategori resiko 1 \\
\hline
\end{tabular}

Tabel 10 Metode Perbaikan Aktivitas Membawa Operator 1

\begin{tabular}{l|l}
\hline \multicolumn{1}{c|}{ Metode Awal } & \multicolumn{1}{c}{ Metode Perbaikan } \\
\hline Punggung membungkuk ke depan & Punggung tegak \\
\hline Kedua lengan berada dibawah bahu & Kedua lengan berada dibawah bahu \\
\hline Berdiri dengan kedua kaki lurus & Berdiri dengan kedua kaki lurus \\
\hline Berat badan sebesar 25 Kg 3 & Berat badan sebesar 25 Kg \\
\hline Kode 2143 & Kode 1123 \\
\hline Kategori resiko 3 & Kategori resiko 1 \\
\hline
\end{tabular}

Tabel 11 Metode Perbaikan Aktivitas Mengangkat Operator 2

\begin{tabular}{l|l}
\hline \multicolumn{1}{c}{ Metode Awal } & \multicolumn{1}{c}{ Metode Perbaikan } \\
\hline Punggung membungkuk ke depan & Punggung tegak \\
\hline Kedua lengan berada dibawah bahu & Kedua lengan berada dibawah bahu \\
\hline Berdiri dengan kedua kaki lurus & Berdiri dengan kedua kaki lurus \\
\hline Berat badan sebesar 22 Kg & Berat badan sebesar 22 Kg \\
\hline Kode 2123 & Kode 1123 \\
\hline Kategori resiko 3 & Kategori resiko 1 \\
\hline
\end{tabular}

Tabel 12 Metode Perbaikan Aktivitas Membawa Operator 2

\begin{tabular}{l|l}
\hline \multicolumn{1}{c}{ Metode Awal } & \multicolumn{1}{c}{ Metode Perbaikan } \\
\hline Punggung membungkuk ke depan & Punggung tegak \\
\hline Kedua lengan berada dibawah bahu & Kedua lengan berada dibawah bahu \\
\hline Kedua kaki bergerak atau berpindah & Kedua kaki bergerak atau berpindah \\
\hline Berat badan sebesar 22 Kg & Berat badan sebesar 22 Kg \\
\hline Kode 1123 & Kode 1173 \\
\hline Kategori resiko 2173 & Kategori resiko 1 \\
\hline
\end{tabular}

Tabel 13 Metode Perbaikan Aktivitas Menurunkan Operator 2

\begin{tabular}{l|l}
\hline \multicolumn{1}{c|}{ Metode Awal } & \multicolumn{1}{c}{ Metode Perbaikan } \\
\hline Punggung membungkuk ke depan & Punggung tegak \\
\hline Kedua lengan berada dibawah bahu & Kedua lengan berada dibawah bahu \\
\hline Berdiri dengan kedua kaki lurus & Berdiri dengan kedua kaki lurus \\
\hline Berat badan sebesar 22 Kg & Berat badan sebesar 22 Kg \\
\hline Kode 2143 & Kode 1123 \\
\hline Kategori resiko 3 & Kategori resiko 1 \\
\hline
\end{tabular}


Tabel 14 Metode Perbaikan Aktivitas Mengangkat Operator 3

\begin{tabular}{l|l}
\multicolumn{1}{c|}{ Metode Awal } & \multicolumn{1}{c}{ Metode Perbaikan } \\
\hline Punggung membungkuk ke depan & Punggung tegak \\
\hline Kedua lengan berada dibawah bahu & Kedua lengan berada dibawah bahu \\
\hline Berdiri dengan kedua lutut sedikit tertekuk & Berdiri dengan kedua kaki lurus \\
\hline Berat badan sebesar $18 \mathrm{Kg}$ & Berat badan sebesar $18 \mathrm{Kg}$ \\
\hline Kode 2152 & Kode 1122 \\
\hline Kategori resiko 3 & Kategori resiko 1 \\
\hline
\end{tabular}

Tabel 15 Metode Perbaikan Aktivitas Membawa Operator 3

\begin{tabular}{l|l}
\multicolumn{1}{c|}{ Metode Awal } & \multicolumn{1}{c}{ Metode Perbaikan } \\
\hline Punggung membungkuk ke depan & Punggung tegak \\
\hline Kedua lengan berada dibawah bahu & Kedua lengan berada dibawah bahu \\
\hline Kedua kaki bergerak atau berpindah & Kedua kaki bergerak atau berpindah \\
\hline Berat badan sebesar $18 \mathrm{Kg}$ & Berat badan sebesar $18 \mathrm{Kg}$ \\
\hline Kode 2172 & Kode 1172 \\
\hline Kategori resiko 2173 & Kategori resiko 1 \\
\hline
\end{tabular}

Tabel 16 Metode Perbaikan Aktivitas Menurunkan Operator 3

\begin{tabular}{l|l}
\multicolumn{1}{c|}{ Metode Awal } & \multicolumn{1}{c}{ Metode Perbaikan } \\
\hline Punggung membungkuk ke depan & Punggung tegak \\
\hline Kedua lengan berada dibawah bahu & Kedua lengan berada dibawah bahu \\
\hline Berdiri dengan kedua kaki lurus & Berdiri dengan kedua kaki lurus \\
\hline Berat badan sebesar $18 \mathrm{Kg}$ & Berat badan sebesar $18 \mathrm{Kg}$ \\
\hline Kode 2142 & Kode 1123 \\
\hline Kategori resiko 3 & Kategori resiko 1 \\
\hline
\end{tabular}

\subsection{Perbaikan Metode kerja}

Perbaikan metode kerja merupakan salah satu tindakan korektif yang dilakukan dengan menerapkan metode kerja yang lebih efektif dan efisien untuk mencegah atau mengurangi resiko musculoskeletal disorders pada operator mesin laminasi tersaji pada tabel 9 sampai 16.

\subsection{Perancangan Fasilitas Kerja}

Perancangan fasilitas kerja disesuaikan dengan kebutuhan operator mesin Laminasi berdasarkan hasil pengolahan data, serta mempertimbangkan batasan angkat yang boleh diangkat dan frekuensi pengangkatan yang dilakukan setiap hari.
Penentuan persentil dilakukan agar rancangan fasilitas kerja dapat digunakan sesuai dengan ukuran tubuh operator mesin laminasi, penentuan toleransi dilakukan untuk menambah kenyamanan pemakaian fasilitas kerja yang akan dirancang, serta penentuan dimensi fasilitas kerja diperlukan agar desain fasilitas yang dirancang akan memberikan rasa nyaman kepada operator mesin laminasi saat melakukan aktivitas pemindahan material. Dimensi rancangan yang diperlukan pada tabel 17 untuk Troly dan tabel 18 untuk Meja. 
Tabel 17 Rekapitulasi Penentuan Persentil dan Penentuan Dimensi Fasilitas Kerja (Troli)

\begin{tabular}{|c|c|c|c|c|c|}
\hline $\begin{array}{c}\text { Dimensi } \\
\text { Tubuh }\end{array}$ & $\begin{array}{c}\text { Nilai } \\
\text { Persentil } \\
\text { yang } \\
\text { dipilih } \\
\end{array}$ & Toleransi & $\begin{array}{c}\text { Ukuran } \\
\text { Rancangan }\end{array}$ & Keterangan & Alasan \\
\hline $\begin{array}{l}\text { Tinggi Siku } \\
\text { Berdiri } \\
\text { (TSB) }\end{array}$ & P50 & - & $104 \mathrm{~cm}$ & - & $\begin{array}{l}\text { Agar pekerja yang } \\
\text { memiliki tubuh } \\
\text { tinggi maupun } \\
\text { pendek dapat } \\
\text { menggunakan troli } \\
\text { dengan nyaman. }\end{array}$ \\
\hline $\begin{array}{l}\text { Tinggi } \\
\text { Pinggul } \\
\text { Berdiri } \\
\text { (TPLB) }\end{array}$ & P50 & $+30 \mathrm{~cm}$ & $94 \mathrm{~cm}$ & $\begin{array}{c}+30 \mathrm{~cm} \\
\text { ditambahkan } \\
\text { untuk jarak } \\
\text { pegangan } \\
\text { troli ke } \\
\text { keranjang } \\
\text { troli. }\end{array}$ & $\begin{array}{l}\text { Agar pekerja yang } \\
\text { memiliki tubuh } \\
\text { tinggi lebih tinggi } \\
\text { posisi punggung } \\
\text { tidak membungkuk } \\
\text { saat mengambil atau } \\
\text { menurunkan } \\
\text { material dari atas } \\
\text { troli dan pekerja } \\
\text { yang memiliki } \\
\text { tubuh pendek tidak } \\
\text { sulit atau } \\
\text { mengambil atau } \\
\text { menurunkan } \\
\text { material dari atas } \\
\text { troli. }\end{array}$ \\
\hline $\begin{array}{l}\text { Diameter } \\
\text { Lingkar } \\
\text { Genggam } \\
\text { (DLG) }\end{array}$ & P50 & - & $3 \mathrm{~cm}$ & - & $\begin{array}{lr}\text { Agar pekerja yang } \\
\text { memiliki diameter } \\
\text { genggam } \\
\text { dapat menggunakan } \\
\text { troli } \\
\text { nyaman. }\end{array}$ \\
\hline $\begin{array}{c}\text { Panjang } \\
\text { Troli }\end{array}$ & - & $5 \mathrm{~cm}$ & $120 \mathrm{~cm}$ & $\begin{array}{l}+5 \mathrm{~cm} \text { untuk } \\
\text { jarak tiap } \\
\text { material }\end{array}$ & $\begin{array}{lr}\text { Agar } & \text { mudah } \\
\text { mengambil } & \text { material } \\
\text { yang } & \text { akan } \\
\text { dipindahkan. } & \\
\end{array}$ \\
\hline Lebar Troli & - & $20 \mathrm{~cm}$ & $65 \mathrm{~cm}$ & $\begin{array}{c}+20 \mathrm{~cm} \\
\text { untuk jarak } \\
\text { dus plastik } \\
\text { roll }\end{array}$ & $\begin{array}{l}\text { Agar saat } \\
\text { pemindahan } \\
\text { hangtag laminasi } \\
\text { lebar troli memuat } 2 \\
\text { tumpukan hantag } \\
\text { laminasi, sedangkan } \\
\text { saat pemindahan } \\
\text { dua plastik roll } \\
\text { hanya memuat } 1 \\
\text { dus posisi } \\
\text { horizontal }\end{array}$ \\
\hline
\end{tabular}


Tabel 18 Rekapitulasi Penentuan Persentil danPenentuan Dimensi Fasilitas Kerja (Meja)

\begin{tabular}{|c|c|c|c|c|c|}
\hline $\begin{array}{l}\text { Dimensi } \\
\text { Tubuh }\end{array}$ & $\begin{array}{c}\text { Nilai } \\
\text { Persentil } \\
\text { yang } \\
\text { dipilih } \\
\end{array}$ & Toleransi & $\begin{array}{c}\text { Ukuran } \\
\text { Rancangan }\end{array}$ & Keterangan & Alasan \\
\hline $\begin{array}{l}\text { Tinggi } \\
\text { Pinggul } \\
\text { Berdiri } \\
\text { (TPLB) }\end{array}$ & P50 & - & $94 \mathrm{~cm}$ & - & $\begin{array}{l}\text { Agar pekerja yang } \\
\text { memiliki tubuh } \\
\text { lebih tinggi posisi } \\
\text { punggung tidak } \\
\text { membungkuk saat } \\
\text { mengambil atau } \\
\text { menurunkan } \\
\text { material dari atas } \\
\text { meja dan pekerja } \\
\text { yang memiliki } \\
\text { tinggi tubuh pendek } \\
\text { tidak sulit saat } \\
\text { mengambil atau } \\
\text { menurunkan } \\
\text { material dari atas } \\
\text { meja. }\end{array}$ \\
\hline $\begin{array}{c}\text { Panjang } \\
\text { Meja Dus } \\
\text { Plastik Roll }\end{array}$ & - & $5 \mathrm{~cm}$ & $140 \mathrm{~cm}$ & $\begin{array}{l}+5 \mathrm{~cm} \text { untuk } \\
\text { jarak tiap } \\
\text { dus plastik } \\
\text { roll. }\end{array}$ & $\begin{array}{lr}\text { Agar } & \text { mudah } \\
\text { mengambil material } \\
\text { yang } & \text { akan } \\
\text { dipindahkan. } & \end{array}$ \\
\hline $\begin{array}{c}\text { Lebar Meja } \\
\text { Dus Plastik } \\
\text { Roll }\end{array}$ & - & $5 \mathrm{~cm}$ & $70 \mathrm{~cm}$ & $\begin{array}{l}+5 \mathrm{~cm} \text { untuk } \\
\text { jarak tiap } \\
\text { dus plastik } \\
\text { roll. }\end{array}$ & $\begin{array}{lr}\text { Agar } & \text { mudah } \\
\text { mengambil material } \\
\text { yang } & \text { akan } \\
\text { dipindahkan. } & \end{array}$ \\
\hline $\begin{array}{l}\text { Panjang } \\
\text { Meja } \\
\text { Hangtag } \\
\text { Laminasi } \\
\end{array}$ & - & $5 \mathrm{~cm}$ & $120 \mathrm{~cm}$ & $\begin{array}{c}+5 \mathrm{~cm} \text { untuk } \\
\text { jarak tiap } \\
\text { hangtag } \\
\text { laminasi } \\
\end{array}$ & $\begin{array}{lr}\text { Agar } & \text { mudah } \\
\text { mengambil } & \text { material } \\
\text { yang } & \text { akan } \\
\text { dipindahkan. } & \\
\end{array}$ \\
\hline $\begin{array}{l}\text { Lebar Meja } \\
\text { Hangtag } \\
\text { Laminasi }\end{array}$ & - & $5 \mathrm{~cm}$ & $70 \mathrm{~cm}$ & $\begin{array}{c}+5 \text { cm untuk } \\
\text { jarak tiap } \\
\text { hangtag } \\
\text { laminasi }\end{array}$ & $\begin{array}{lr}\text { Agar } & \text { mudah } \\
\text { mengambil material } \\
\text { yang } \\
\text { dipindahkan. }\end{array}$ \\
\hline
\end{tabular}

\subsection{Pemodelan Hasil Rancangan}

Pemodelan hasil rancangan dibuat untuk mengetahui metode kerja operator mesin dalam melakukan perpindahan material setelah dilakukan perancagan fasilitas kerja berupa meja dan troli pada Gambar 8 sampai 13.

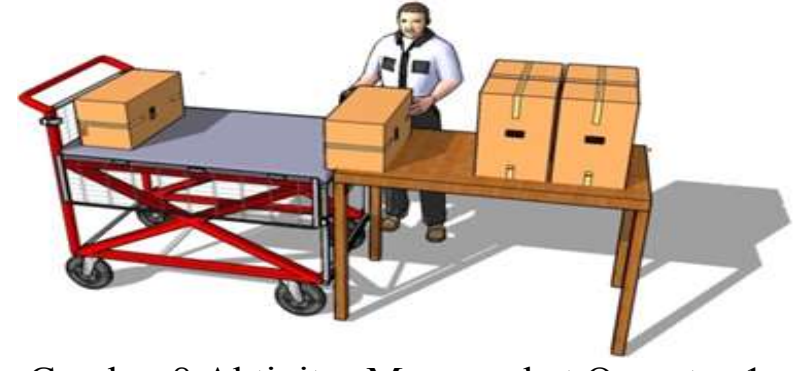

Gambar 8 Aktivitas Mengangkat Operator 1

Setelah Perancangan Fasilitas Kerja. 


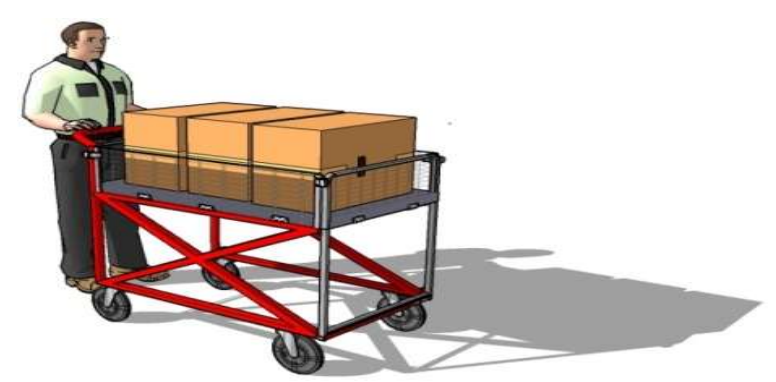

Gambar 9 Aktivitas Mengangkat Operator 1 Setelah Perancangan Fasilitas Kerja.

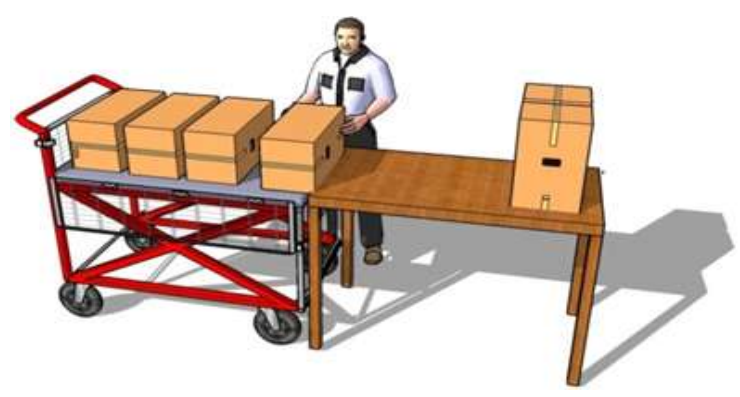

Gambar 10 Aktivitas Menurunkan Operator 1 Setelah Perancangan Fasilitas Kerja.

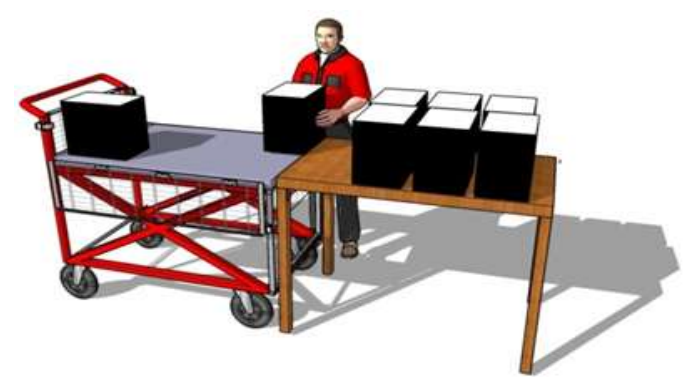

Gambar 11 Aktivitas Mengangkat Operator 2 Setelah Perancangan Fasilitas Kerja.

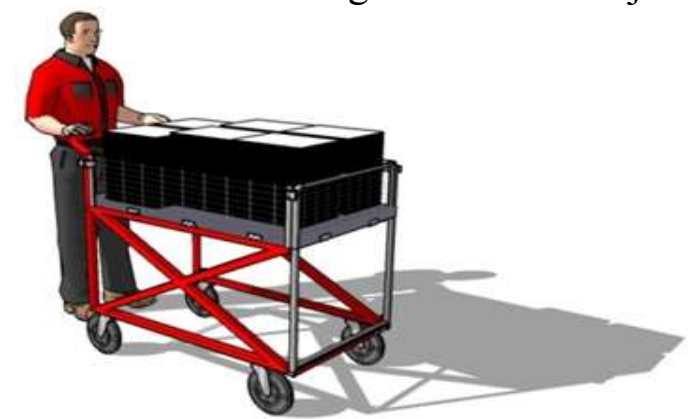

Gambar 12 Aktivitas Membawa Operator 2 Setelah Perancangan Fasilitas Kerja

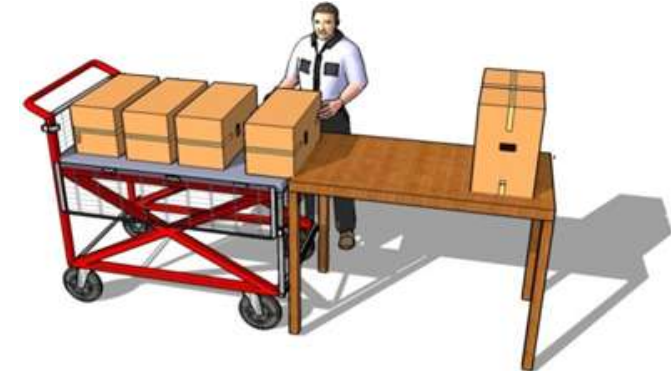

Gambar 13 Aktivitas Menurunkan Operator 2 Setelah Perancangan

Fasilitas Kerja

\section{KESIMPULAN DAN SARAN}

1. Berdasarkan hasil penyebaran kuesioner Nordic Body Map metode kerja pada aktivitas pemindahan material yang dilakukan oleh operator mesin laminasi saat ini menimbulkan keluhan pada bagian tubuh dengan persentasi keluhan terbanyak terdapat pada bagian leher atas dan leher bawah, betis kanan dan betis kiri, serta punggung.

2. Hasil dari penentuan kategori resiko kerja secara manual didapatkan hampir seluruh kegiatan yang dilakukan ketiga operator Mesin Laminasi dalam pemindahan material mulai dari mengangkat, membawa, dan menurunkan termasuk pada kategori resiko 3 (tiga) yaitu posisi dengan efek berbahaya pada sistem muskuloskeletal (resiko tinggi).

3. Tindakan korektif yang dilakukan untuk mengurangi atau mencegah keluhan musculoskeletal disorders pada operator Mesin Laminasi yaitu dengan perancangan fasilitas kerja dan perbaikan metode kerja. Fasilitas kerja yang dirancang berupa meja dan troli.. Perbaikan metode kerja dan perancangan fasilitas kerja dapat menurunkan kategori resiko kerja operator mesin laminasi menjadi kategori resiko 1 (satu) yaitu posisi normal tanpa efek yang dapat mengganggu sistem muskuloskeletal (resiko rendah). 


\section{DAFTAR PUSTAKA}

Anggraini, Wresni dan Mulya Pratama, Anda., 2012. Analisis Postur Kerja Dengan Menggunakan Metode Ovako Working Analysis System (OWAS) Pada Stasiun Pengepakan Bandela Karet (Studi Kasus di PT. Riau Crumb Rubber Factory Pekanbaru). Jurnal Sains, Teknologi dan Industri, Vol. 10 No.1.

Hartono, Markus, 2012. Panduan Survei Data Anthropometri, Jurusan Teknik Industri Universitas Surabaya.

Nurhayuning J., Rovayana dan Paskarini, Indiyati, 2015. Hubungan Posisi kerja dengan Keluhan Muskuloskleletal pada Unit Pengelasan PT X Bekasi, The Indonesian Journal of Occupational Safety and Health, Vol. 4, No. 1, 2015, Jan - Jun, 33-42.

Nurmianto, Eko, Ergonomi, 1996. Konsep Dasar dan Aplikasinya, PT Guna Widya. Surabaya.

Sutalaksana, I.Z., Anggawisastra, R., dan Tjakraatmadja J.H. 2006. Teknik Perancangan Sistem Kerja. Penerbit ITB, Bandung.

Tarwaka dkk. 2004. Ergonomi untuk Keselamatan, Kesehatan Kerja dan Produktivitas, Uniba Press, Surakarta.

Ulfah, Nur, Harwanti, Siti, Nur, Joko Nurcahyo., Panuwun, 2014. Sikap Kerja dan Risiko Musculoskeletal Disoeders pada Pekerja Laundry, Jurnal Kesehatan Masyarakat Nasional, Vol 8 No. 7, Februari.

Wijaya, Andi, 2008. Analisis Postur Kerja dan Perancangan Alat Bantu Untuk Aktivitas Manual Material Handling Industri Kecil (Studi Kasus: Industri Kecil Pembuatan Tahu di Kartasuro), Tugas Akhir, Jurusan Teknik Industri Fakultas Teknik Universitas Muhammadiyah Surakarta. 